\title{
Role of Arachidonate Lipoxygenase and Cyclooxygenase Products in Insulin and Glucagon Secretion From Rat Pancreatic Islets
}

\author{
Reginald O. Morgan and Sumer Belbez Pek
}

\begin{abstract}
Rat pancreatic islets incubated in nutrient medium were used to study the role of endogenous arachidonic acid metabolism in pancreatic hormone secretion. Both glucose and fetal calf serum stimulated radioimmunoassayable PGE $_{2}$ production and insulin secretion from islets. These effects were abolished by the phospholipase inhibitor p-bromophenacyl bromide or by concurrent inhibition of cyclooxygenase and lipoxygenase by flurbiprofen plus nordihydroguaiaretic acid (NDGA). respectively. Bromophenacyl bromide also inhibited glucagon secretion. When used alone, flurbiprofen caused a significant enhancement of glucose-induced insulin secretion that was attributed to reactive stimulation of lipoxygenase-product formation rather than to selective cyclooxygenase inhibition. NDGA given alone in the presence of stimulatory concentrations of glucose suppressed the normal eight-fold rise in insulin secretion, but caused a marked enhancement in glucagon secretion that could be overcome by simultaneous inclusion of flurbiprofen. We concluded that: (1) Increased metabolism of arachidonic acid in pancreatic islets amplifies the secretion of insulin and glucagon. (2) The lipoxygenase as well as the cyclooxygenase pathways of arachidonate metabolism participate in the amplification of insulin secretion. (3) The observations made in this study are inconclusive with respect to the involvernent of the lipoxygenase and cyclooxygenase pathways in glucagon secretion; an inhibitory role for lipoxygenase pathway products is suggested.
\end{abstract}

$\mathbf{G}^{\mathrm{L}}$ UCOSE, the paramount stimulator of insulin release, enhances the hydrolysis of phospholipids and the metabolism of arachidonic acid in pancreatic islets. ${ }^{2-4}$ Phospholipase $A_{2}$, the enzyme that liberates arachidonate from the phospholipid stores stimulates insulin release. ${ }^{5}$ Arachidonate metabolism is stimulated also by phorbol esters, ${ }^{6}$ furosemide, ${ }^{7}$ methylxanthine, ${ }^{8}$ and fetal calf serum, ${ }^{9}$ which are agents with diverse biological actions. Also, insulin secretion is stimulated by phorbol esters, ${ }^{6}$ furosemide, ${ }^{10}$ methylxanthines, ${ }^{11}$ and fetal calf serum. ${ }^{12}$ Conversely, agents associated with inhibition of phospholipid and arachidonate metabolism, including glucocorticoids, ${ }^{13}$ diphenylhydantoin, ${ }^{14}$ and quinacrine, ${ }^{10}$, inhibit insulin secretion. The implication is that changes in membrane phospholipids or increases in arachidonate metabolites may play a stimulatory role in insulin secretion.

Many in vitro studies support the view that prostaglandins (PGs) may serve as positive modulators in the secretion of insulin, glucagon, and somatostatin. ${ }^{15-21}$ Nevertheless, the physiological significance and even the qualitative role of endogenous cyclooxygenase products as regulators of islet hormone secretion remain to be established. ${ }^{12,22}$ At variance with the view of prostaglandins as agents which promote insulin

From the Department of Internal Medicine (Division of Endocrinology and Metabolism), The University of Michigan, Ann Arbor. Mich.

This work was presented in part and published in abstract form in conjunction with the Fifth International Conference on Prostaglandins. ${ }^{1}$

Address reprint requests to Sumer Belbez Pek, MD, D4113 SACB, Box 02 University of Michigan Hospitals, Ann Arbor, MI 48109.

(c) 1984 by Grune \& Stratton, Inc.

0026-0495/84/3310-0009\$03.00/0 secretion are the findings that cyclooxygenase inhibitors often increase rather than decrease insulin secretion $^{23.24}$ and that elevated prostaglandin levels may sometimes be associated with suppression of insulin secretion. ${ }^{25,26}$

Recently, lipoxygenase enzymes that are involved in arachidonate metabolism have been shown to be glucose sensitive. ${ }^{27}$ Lipoxygenase activity in pancreatic islets accounts for substantial production of nonprostanoid metabolites of arachidonic acid. ${ }^{3}$ In view of the growing evidence for an important permissive or stimulatory role of lipoxygenase products in secretagogue action in other glands ${ }^{28}$ we have undertaken a pharmacological evaluation of a regulatory role for endogenous eicosanoids in islet-hormone secretion.

\section{MATERIALS AND METHODS}

Intact pancreatic islets were isolated from young adult, male, fed Sprague-Dawley rats (Charles River Laboratories, Wilmington, MA), by the method of Lacy and Kostianovsky. ${ }^{29}$ A standard polystyrene tissue culture plate with $960.3-\mathrm{mL}$ round-bottomed wells served as the incubation vessel. Each well contained $0.3 \mathrm{~mL}$ Waymouth MD-705/1 tissue culture medium (Gibco, special formulation) supplemented with $1 \mathrm{mg} / \mathrm{mL}$ bovine serum albumin Control "blank" wells received no islets. Five islets were transferred into each of the other wells. Four wells were assigned to each treatment condition.

The experimental protocols were designed to induce various levels of activation of phospholipase $A_{2}$ and stimulation of insulin release by employing glucose at concentrations of $4,6,9,13$ and $20 \mathrm{mmol} /$ $\mathrm{L}$, and no glucose as a control. Fetal calf serum (FCS 10,30 or 100 $\mu \mathrm{l} / \mathrm{mL}$ ) was also employed to activate phospholipase $\mathbf{A}_{2} .{ }^{9}$ Whenever FCS was employed, 100 kallikrein inhibitor units of aprotinin was added to the media in order to protect glucagon. In one experiment, exogenous arachidonic acid (Sigma) was added to the incubation media $(10,40$ and $100 \mu \mathrm{mol} / \mathrm{L})$ in the presence of $1 \mathrm{mg} / \mathrm{mL}$ albumin to ascertain that hormone release occurred when this fatty acid was in abundance. The following drugs were used to inhibit maximally various enzymes involved in arachidonic acid metabolism: (1) 40 $\mu \mathrm{mol} / \mathrm{L}$ p-bromo-phenacyl bromide (BPB, Sigma) to inhibit phospholipase $\mathbf{A}_{2},{ }^{30}$ (2) $10 \mu \mathrm{mol} / \mathrm{L}$ flurbiprofen (FLR, Upjohn) to inhibit 
cyclooxygenase, ${ }^{31,32}$ and (3) $40 \mu \mathrm{mol} / \mathrm{L}$ nordihydroguaiaretic acid (NDGA, Sigma) to inhibit lipoxygenases. ${ }^{33-36}$

The plates were kept for 20 hours in an incubator at $37^{\circ} \mathrm{C}$ and an atmosphere of $5 \%$ carbon dioxide and $95 \%$ air. The length of the incubation period was calibrated to allow sufficient prostaglandins to accumulate in the media so that their levels could be measured in radioimmunoassay (RIA). Upon completion of the incubations, $10-\mu \mathrm{L}$ aliquots of the media were submitted to insulin and glucagon RIAs. ${ }^{37}$ For the RIA of $\mathrm{PGE}_{2},{ }^{38} 250-\mu \mathrm{L}$ aliquots from quadruplicate wells were pooled and extracted as follows. An equal volume of acetonitrile was added to each sample, in order to extract lipids and then to dehydrate proteins. The mixture was vortexed and centrifuged to precipitate the protein. The liquid phase was removed and acidified with formic acid ( $\mathrm{pH} 3.5$ ). To remove nonpolar, nonhydroxylated fats, $3 \mathrm{~mL}$ of petroleum ether was added; the tube was vortexed and centrifuged. The lower aqueous layer was removed and submitted to petroleum ether extraction a second time. The aqueous layer was mixed with $4 \mathrm{~mL}$ ethyl acetate. The mixture was centrifuged, the upper ethyl-acetate layer containing eicosanoids was removed and saved. The aqueous layer was treated a second time with ethyl acetate. The ethyl-acetate layers were combined and dried in air at room temperature. Recovery of prostanoids was estimated by the recovery of ${ }^{3} \mathrm{H}-\mathrm{TXB}_{2}$ which had been added to each sample prior to extraction; it was around $80 \%$. When unlabeled $\mathrm{PGE}_{2}$ was added to incubation media containing either albumin or FCS prior to the extraction process, $75 \%$ to $90 \%$ of it was recovered in the RIA. The limit of sensitivity of the RIA for PGE $_{2}$ was 5.7 femtomoles per tube (fmol/tube). When the media in the islet-free blank wells contained fetal calf serum, the $\mathrm{PGE}_{2}$ immunoreactivity increased proportionate to the concentration of FCS. Based on these measurements, the concentration of $\mathrm{PGE}_{2}$ in the FCS was $12 \pm 8 \mathrm{nmol} / \mathrm{L}$.

The numbers of observations refer to experiments conducted using separate batches of islets; each observation was made in quadruplicate. The samples were radioimmunoassayed in duplicate; the data represent values after the subtraction of concentrations detected in the islet-free incubation media from the corresponding experimental islet-containing media. They are given as the means \pm standard errors of the mean (SEM), and expressed as fmol per islet per hour. This unit of expression is conventional and is intended to adjust for differences in experimental protocols with respect to islet density and duration of incubation; steady secretion rates are not implied. The significance of the differences were determined using analysis of variance among the replicates (four values per observation) and Duncan's multiple-range tests ${ }^{39}$ for the hormone results, and Dunnett's $t$ test ${ }^{40}$ for the $\mathrm{PGE}_{2}$ data derived from pooled samples (one value per observation representing four incubation wells). A probability of identity of less than 0.05 by two-tailed distribution was accepted as statistically significant.

\section{RESULTS}

\section{Effect of Arachidonic Acid}

To determine whether in this model of islet cells the abundance of arachidonate evokes increased synthesis of PGs and release of insulin and glucagon, the islets were incubated without and with 10,40 or $100 \mu \mathrm{mol} / \mathrm{L}$ exogenous arachidonic acid in the presence of $9 \mathrm{mmol} /$ $\mathrm{L}$ glucose and $1 \mathrm{mg} / \mathrm{mL}$ albumin (Fig 1). As compared to incubate levels in the absence of arachidonate, $\mathrm{PGE}_{2}$, insulin, and glucagon release increased with 100 $\mu \mathrm{mol} / \mathrm{L}$ arachidonate. Only insulin release increased with $40 \mu \mathrm{mol} / \mathrm{L}$ arachidonate; $10 \mu \mathrm{mol} / \mathrm{L}$ of the fatty

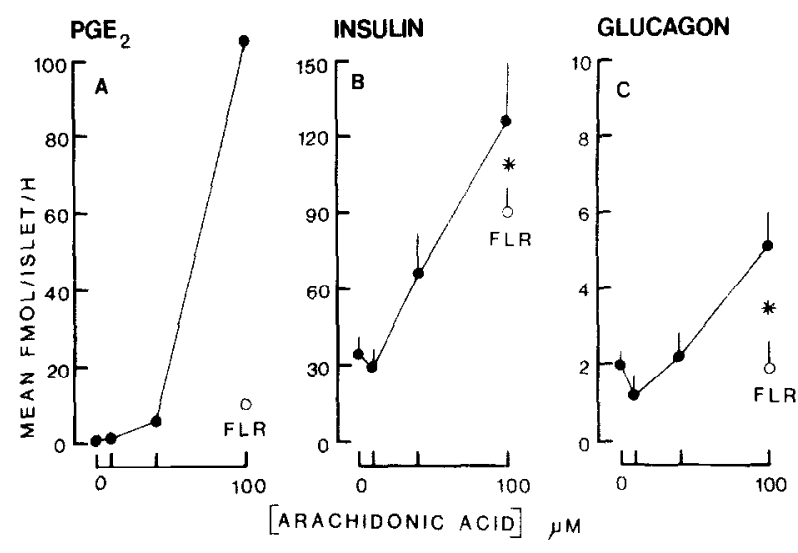

Fig 1. Release of immunoreactive $\operatorname{PGE}_{2}(A)$, insulin (B), and glucagon (C) from incubated rat islets in the presenca of $9 \mathrm{mmol} / \mathrm{L}$ glucose, $1 \mathrm{mg} / \mathrm{mL}$ albumin and $0,10,40$ or $100 \mu \mathrm{mol} / \mathrm{L}$ arachidonic acid (closed circles) in one experiment. In a parallel experiment depicted by the open circles, the media also contained 1 $\mu \mathrm{mol} / \mathrm{L}$ flurbiprofen (FLR). Asterisks denote statistically significant differences between the quadruplicate values obtained with $100 \mu \mathrm{mol} / \mathrm{L}$ arachidonate, in the presence or absence of FLR (statistical assessment of the $\mathrm{PGE}_{2}$ data was not possible because the samples were pooled).

acid had no effect on any of the parameters. In a concurrently conducted experiment, the islets were incubated with $100 \mu \mathrm{mol} / \mathrm{L}$ arachidonic acid plus 1 $\mu \mathrm{mol} / \mathrm{L}$ flurbiprofen. With flurbiprofen, the release of $\mathrm{PGE}_{2}$, insulin, and glucagon decreased toward or to levels observed in the absence of arachidonate.

\section{Effect of Fetal Calf Serum}

FCS at the concentration of $100 \mu \mathrm{L} / \mathrm{mL}$ was used as a probe to stimulate phospholipase $A_{2}$ and thus to induce an abundance of endogenous arachidonic acid (Fig 2). ${ }^{9}$ In addition, presumably FCS itself contained some arachidonate that further enriched the arachidonate pool. Albumin $(1 \mathrm{mg} / \mathrm{mL})$ rather than serum was the additive in the control wells. With FCS, the release of $\mathrm{PGE}_{2}$ from islets increased 15- to 17-fold at 0 and $4 \mathrm{mmol} / \mathrm{L}$ glucose, and 24 - to 34 -fold in the presence of 6 to $20 \mathrm{mmol} / \mathrm{L}$ glucose. The lowest concentration of glucose that evoked significant increases in insulin release was $9 \mathrm{mmol} / \mathrm{L}$ without and $6 \mathrm{mmol} / \mathrm{L}$ with FCS. FCS augmented insulin release to $130 \%, 216 \%$ and $161 \%$ of controls at 4,6 , and 9 $\mathrm{mmol} /$ glucose, respectively. The release of glucagon did not appear to be influenced by either the prevailing concentration of glucose or by the presence or absence of FCS.

\section{Effect of p-Bromophenacyl Bromide}

In order to elucidate further the role of phospholipase $A_{2}$ in islet hormone secretion, BPB was utilized at the concentration of $40 \mu \mathrm{mol} / \mathrm{L}$, considered to be sufficient to inhibit the enzyme maximally (Fig 3). ${ }^{30}$ 


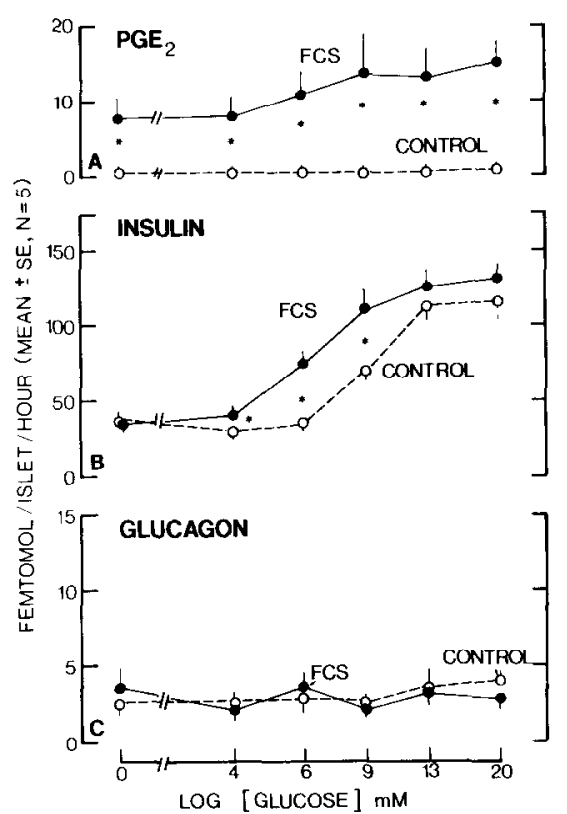

Fig 2. Release of immunoreactive $\mathrm{PGE}_{2}(\mathrm{~A})$, insulin (B). and glucagon (C) from incubated rat islets at six concentrations of glucose in the presence of $1 \mathrm{mg} / \mathrm{mL}$ bovine serum albumin (Control) or $100 \mu \mathrm{L} / \mathrm{mL}$ fetal calf serum (FCS). Asterisks denote statistically significant differences between corresponding experimental and control data points. In control experiments, PGE, release with 13 and $20 \mathrm{mmol} / \mathrm{L}$ glucose was significantly greater than that without glucose.

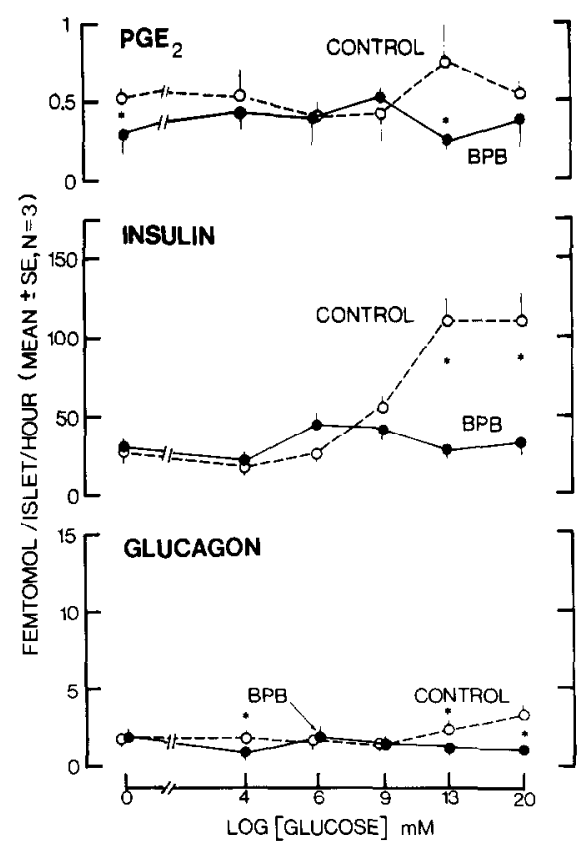

Fig 3. Release of $\mathrm{PGE}_{2}$, insulin, and glucagon from incubated islets at six concentrations of glucose without (Control) or with 40 $\mu \mathrm{mol} / \mathrm{L}$ p-bromo-phenacyl bromide (BPB). Media contained $1 \mathrm{mg} /$ $\mathrm{mL}$ albumin. Asterisks denote significant differences between corresponding experimental and control data points. In control experiments, $\mathrm{PGE}_{2}$ release with $13 \mathrm{mmol} / \mathrm{L}$ glucose was significantly greater than that without glucose.
The incubation media contained $1 \mathrm{mg} / \mathrm{mL}$ albumin but no FCS. BPB inhibited $\mathrm{PGE}_{2}$ release in the absence of glucose (56\% of control) and with 13 $\mathrm{mmol} / \mathrm{L}$ glucose (33\% of control). Insulin release was inhibited by BPB at the two highest concentrations of glucose (at 13 and $20 \mathrm{mmol} / \mathrm{L}, 25 \%$ and $29 \%$ of control, respectively). Glucagon release was also inhibited by BPB: $45 \%, 49 \%$, and $36 \%$ of control, respectively, at 4,13 and $20 \mathrm{mmol} / \mathrm{L}$ glucose.

\section{Effect of Flurbiprofen}

A potent and selective inhibitor of cyclooxygenase, FLR was used at the concentration of $10 \mu \mathrm{mol} / \mathrm{L}$ (Fig 4). At all concentrations of glucose, FLR inhibited $\mathrm{PGE}_{2}$ release in the range of $47 \%$ to $13 \%$ of control. FLR promoted insulin release when glucose concentration was high (with 9,13 and $20 \mathrm{mmol} / \mathrm{L}$ glucose, $130 \%, 163 \%$, and $152 \%$ of control, respectively). Glucagon release was not significantly affected by FLR.

\section{Effect of Nordihydroguaiaretic Acid}

NDGA at the concentration of $40 \mu \mathrm{mol} / \mathrm{L}$ was employed as a probe to inhibit the lipoxygenases (Fig $5)$. In the glucose concentration range of 0 to 9 $\mathrm{mmol} / \mathrm{L}, \mathrm{PGE}_{2}$ release with NDGA was similar to or moderately greater than that observed during control experiments ( $104 \%$ to $213 \%$ of control). At 13 and 20 mmol/L glucose, NDGA inhibited $\mathrm{PGE}_{2}$ release to $60 \%$ and $56 \%$ of control, respectively. Insulin release

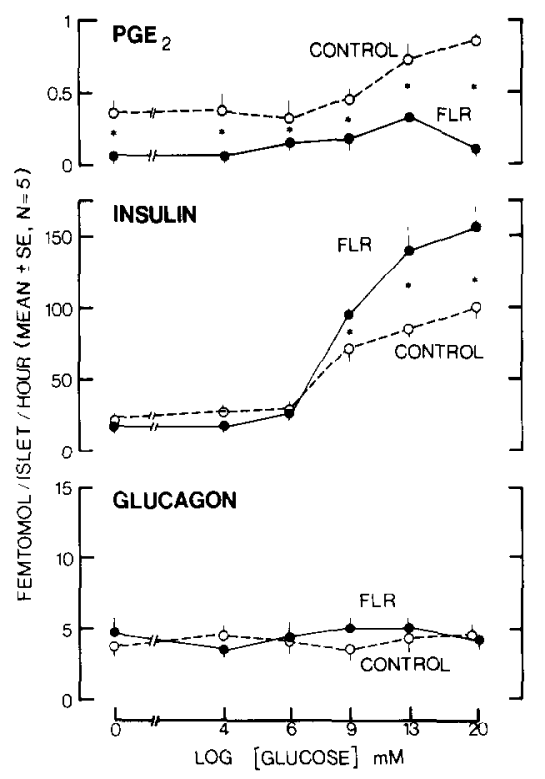

Fig 4. Release of $\mathrm{PGE}_{2}$, insulin, and glucagon from incubated islets at six concentrations of glucose without (Control) and with $10 \mu \mathrm{mol} / \mathrm{L}$ flurbiprofen (FLR). Media contained $1 \mathrm{mg} / \mathrm{mL}$ albumin. Asterisks denote significant differences between corresponding experimental and control data points. In control experiments, $\mathrm{PGE}_{2}$ release with 13 and $20 \mathrm{mmol} / \mathrm{L}$ glucose was significantly greater than that without glucose. 


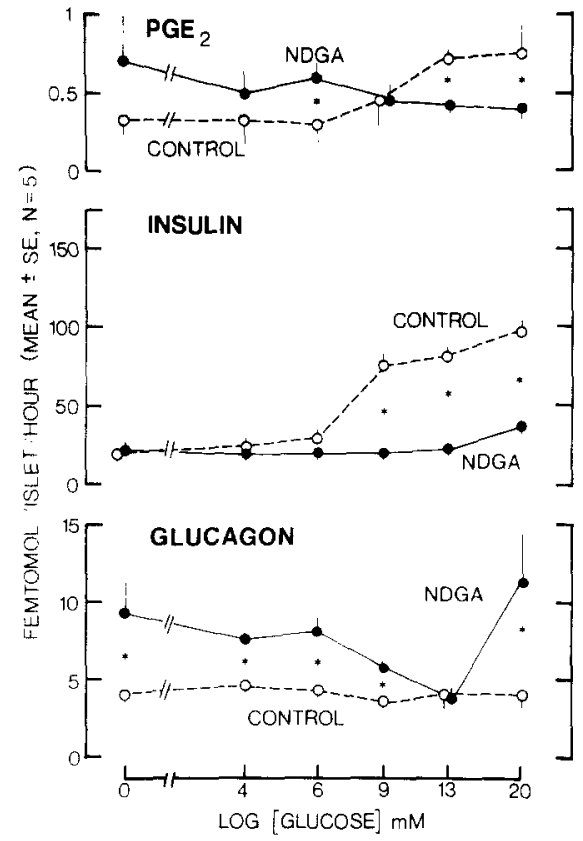

Fig 5. Release of $\mathrm{PGE}_{2}$ insulin, and glucagon from incubated islets at six concentrations of glucose without (Control) and with $40 \mu \mathrm{mol} / \mathrm{L}$ nordihydroguaiaretic acid (NDGA). Media contained 1 $\mathrm{mg} / \mathrm{mL}$ albumin. Asterisks denote significant differences between corresponding experimental and control data points. In control experiments, $\mathrm{PGE}_{2}$ release with 13 and $20 \mathrm{mmol} / \mathrm{L}$ glucose was significantly greater than that without glucose.

was inhibited by NDGA at high concentrations of glucose (at 9 to $20 \mathrm{mmol} / \mathrm{L}, 39 \%$ to $27 \%$ of control). With the exception of $13 \mathrm{mmol} / \mathrm{L}$ glucose, glucagon release was greater with NDGA than without it, in the range of $166 \%$ to $278 \%$ of control.

\section{Effect of Glucose Alone on $\mathrm{PGE}_{2}$ Release}

In order to quantify with precision the promotion of $\mathrm{PGE}_{2}$ release by glucose, the data from the control experiments depicted in Figs 2, 3, 4, and 5 were pooled. In the presence of $1 \mathrm{mg} / \mathrm{mL}$ albumin, with $0,4,6,9,13$ and $20 \mathrm{mmol} / \mathrm{L}$ glucose, $\mathrm{PGE}_{2}$ release was $0.33 \pm 0.01,0.43 \pm 0.07,0.44 \pm 0.02$, $0.46 \pm 0.01,0.68 \pm 0.04$, and $0.68 \pm 0.07 \mathrm{fmol} /$ islet $/$ $\mathrm{h}(\mathrm{N}=18)$, respectively. The analysis of variance revealed a significance level of $P<0.001$. In paired comparisons, the values observed with $6,9,13$ and 20 $\mathrm{mmol} / \mathrm{L}$ glucose were different from the value observed in the absence of glucose $(P<0.05$ to $<0.001)$.

\section{Interactions of Fetal Calf Serum and Enzyme Inhibitors}

In another series of experiments, the concentration of glucose was kept constant at the highest level employed in the preceding experiments $(20 \mathrm{mmol} / \mathrm{L})$ (Fig 6). The concentration of fetal calf serum was

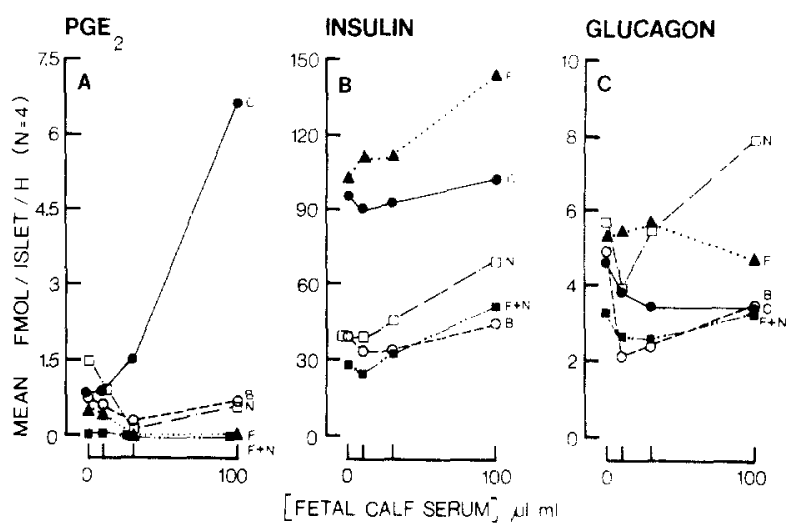

Fig 6. Release of $\mathrm{PGE}_{2}$ (A), insulin (B), and glucagon (C) from incubated islets in the presence of $20 \mathrm{mmol} / \mathrm{L}$ glucose and $0,10,30$ or $100 \mu \mathrm{L} / \mathrm{mL}$ fetal calf serum. $\mathrm{C}=$ control experiments without drug additives. In the other experiments, the following drugs were present in the incubation media: $B=$-bromophenacyl bromide $40 \mu \mathrm{mol} / \mathrm{L} ; \mathrm{F}$ = flurbiprofen $10 \mu \mathrm{mol} / \mathrm{L} ; \mathbf{N}=$ nordihydroguaiaretic acid $40 \mu \mathrm{mol} / \mathrm{L}$; and $F+N=$ flurbiprofen $10 \mu \mathrm{mol} / \mathrm{L}$ plus nordihydroguaiaretic acid $40 \mu \mathrm{mol} / \mathrm{L}$. Standard error bars have been omitted to avoid clutter: statistical information is given in the text.

varied from $0,10,30$ to $100 \mu \mathrm{L} / \mathrm{mL}$, in order to induce progressively increasing abundance of arachidonic acid. BPB, FLR, and NDGA were employed individually as in the preceding experiments. In addition, FLR and NDGA were added to the media as a mixture, in order to inhibit respectively the cyclooxygenase as well as the lipoxygenases.

In control experiments, $\mathrm{PGE}_{2}$ release increased progressively as the concentration of FCS increased $(P<0.001$ at 30 or $100 \mu \mathrm{L} / \mathrm{mL} \mathrm{FCS} v$ no FCS $)$. This increase was inhibited completely by either FLR or FLR plus NDGA $(P<0.001)$. NDGA alone inhibited $\mathrm{PGE}_{2}$ release at 30 and $100 \mu \mathrm{L} / \mathrm{mL} \mathrm{FCS} \mathrm{to} \mathrm{about} 10 \%$ of control $(P<0.05)$. Also BPB inhibited $\mathrm{PGE}_{2}$ release to $70 \%$ to $10 \%$ of control $(P<0.05$ to 0.01$)$.

The increases in insulin release associated with the increases in FCS levels were much less than the increases in $\mathrm{PGE}_{2}$ release; at $100 \mu \mathrm{L} / \mathrm{mL}$ FCS, insulin release was $118 \%(\mathrm{NS})$ and $\mathrm{PGE}_{2}$ release $801 \%$ $(P<0.001)$ of corresponding values without FCS. BPB inhibited insulin release to about $40 \%$ of controls $(P<0.01)$ at all concentrations of FCS. FLR did not modify insulin release in the absence of FCS. In the presence of FCS, FLR augmented insulin release to $122 \%$ to $127 \%$ of control, which was statistically significant $(P<0.05)$ only at $100 \mu \mathrm{L} / \mathrm{mL}$ FCS. NDGA inhibited insulin release at all levels of FCS $(P<0.01)$. Also FLR plus NDGA inhibited the release significantly under all conditions. The range of values were $46 \%$ to $29 \%$ of the corresponding controls without any drugs ( $P<0.05$ to 0.01 ), and $73 \%$ to $63 \%$ of the corresponding values with NDGA alone $(P<0.05)$. 
Glucagon release was not affected significantly by the changes in the levels of FCS. In the absence of FCS, only FLR plus NDGA inhibited glucagon secretion $(P<0.05)$. In the presence of various concentrations of FCS, the effects of the drugs on glucagon secretion were quite variable and did not display any definite patterns; the only value which was significantly different from the corresponding control was that observed in the presence of NDGA and 100 $\mu \mathrm{L} / \mathrm{mL}$ FCS.

\section{DISCUSSION}

The results of our studies indicate that arachidonic acid metabolism in pancreatic islets participates in the regulation of secretion of islet hormones, and that perturbations in this metabolism cause complex changes in hormone release.

We monitored the levels of $\mathrm{PGE}_{2}$ as an index of biosynthetic activity in the cyclooxygenase pathway of arachidonate metabolism. We regard the information on $\mathrm{PGE}_{2}$ levels also as a validation of the occurrence of the anticipated effects of the inhibitor drugs. In order to monitor the levels of immunoreactive $\mathrm{PGE}_{2}$ in the media, the incubation period had to be extended considerably beyond the durations necessary to monitor hormone secretion. Thus, the levels of $\mathrm{PGE}_{2}$, insulin, and glucagon may underestimate the secreted amounts as a result of possible degradation. We attempted to minimize the degradation of glucagon by enzymes present in serum, using aprotinin. Based on information provided by Metz et al in a similar incubation system for neonatal rat pancreatic cells, ${ }^{41}$ we assume that $\mathrm{PGE}_{2}$ was reasonably stable also in our model.

The increases in $\mathrm{PGE}_{2}$ release that occurred with exogenous arachidonate indicate that the islet cells can take up and metabolize this fatty acid to PGs. The abolition of the arachidonate-induced increases in $\mathrm{PGE}_{2}$ release by flurbiprofen, a potent cyclooxygenase inhibitor, adds credence to this interpretation. The dose-related increases in $\mathrm{PGE}_{2}$ production that occurred with glucose or fetal calf serum and particularly with the combination of these agents are consistent with existing evidence that both glucose and FCS activate phospholipase $\mathrm{A}_{2} \cdot{ }^{4,9}$ The marked reduction of the effects of glucose plus FCS by BPB supports the interpretation that the increased level of activity of phospholipase $A_{2}$ and resultant increase in cytosolic arachidonate accompany the administration of glucose and FCS.

The stimulation of insulin and glucagon release with exogenous arachidonate and the inhibition of this effect with flurbiprofen suggest an amplifying role for the metabolites of arachidonate generated in the cyclooxygenase pathway. The stimulatory effect of arachidonate on islet-hormone secretion seen in our experiment corroborate the observations of Metz et $a l^{42}$ on insulin secretion from cultured neonatal rat pancreatic cells and our previous demonstration of the stimulation by arachidonate of insulin and glucagon secretion from the isolated perfused rat pancreas. ${ }^{43}$ The ability of BPB to inhibit insulin and glucagon release under conditions that promote phospholipase $\mathrm{A}_{2}$ activity indicates that the consequent increases in arachidonate levels in the cytosol and ensuing increases in the metabolism of arachidonate play an amplifying role in the secretion of both hormones. The effect of BPB on glucagon release must be interpreted with caution, because glucagon release did not increase in the presence of FCS, a promoter of phospholipase activity. In the FCS experiments, the degrading action of serum on glucagon may have masked any increases, despite the presence of aprotinin in the incubation media. Alternatively, the suppressive action of glucose may have prevented the anticipated increase in glucagon secretion from occurring.

The focus of attention in this study was on the involvement of the cylooxygenase-activated and lipoxygenase-activated products of arachidonate metabolism in the amplification of islet hormone secretion that occurs when arachidonate is in abundance. As pharmacological probes, FLR was used to inhibit the cyclooxygenase and NDGA the lipoxygenases, so that clues may be gained by the process of subtraction.

The fact that FLR inhibited the cyclooxygenase under all of our experimental conditions is evidenced by the decreases in the biosynthesis of $\mathrm{PGE}_{2}$, the major cyclooxygenase product in islets. ${ }^{22}$ At the moment we are not equipped to assess directly whether with NDGA the anticipated inhibition of islet lipoxygenases $^{3}$ was achieved. In other systems, at the concentration employed in this study, NDGA effectively inhibited lipoxygenases. ${ }^{34,35}$ We have no reason to suspect that the same did not occur in our experiments. An issue of concern is the selectivity of the action of NDGA on islet lipoxygenases, because $\mathrm{PGE}_{2}$ release was inhibited by NDGA whenever glucose or fetal calf serum was in abundance. One interpretation of this observation is that NDGA inhibited not only lipoxygenases, but also the cyclooxygenase. Alternatively, the synthesis of prostaglandins decreased secondary to the decreases in lipoxygenase products: Feuerstein et $\mathrm{al}^{44}$ have shown that leukotriene $\mathrm{C}$, a lipoxygenase product, stimulates prostaglandin release from macrophages. Whatever the mechanisms may have been, in evaluating our findings with NDGA, the decreases in cyclooxygenase activity that sometimes occurred should be kept in mind. Similar considerations are 
necessary in evaluating the observed effects of FLR. FLR is one of the most potent and selective inhibitors of cyclooxygenase. ${ }^{31}$ Thus, the issue of concern is the probable consequences of FLR-induced inhibition of cyclooxygenase on the activity in the lipoxygenase pathway, rather than a direct effect of FLR on the lipoxygenases. There is evidence that the inhibition of cyclooxygenase promotes the activity in the lipoxygenase pathways by two mechanisms: ${ }^{36,45}$ (1) Prostaglandins inhibit lipoxygenase activity, so that decreased synthesis in prostaglandins would allow the activity in that pathway to increase. (2) The inhibition of the cyclooxygenase leads to increased metabolism of arachidonate in the lipoxygenase pathways. Thus, also in interpreting the effects of FLR on islet-hormone release, potential changes in both pathways of arachidonate metabolism must be considered. We believe that by comparing the results with FLR or NDGA alone to those obtained by using the two drugs in combination, the involvement of the alternate metabolic pathway in the observed effects can be deduced.

Ten micromolar FLR enhanced glucose-induced insulin release. This observation is consistent with the findings of several other investigators ${ }^{46}$ that cyclooxygenase inhibitors promote glucose-induced insulin release. On the other hand, our present results are in conflict with our own observations in the present experiment with exogenous arachidonate and in other studies that $1 \mu \mathrm{mol} / \mathrm{L}$ FLR inhibited insulin release. ${ }^{22,47,48}$ Inhibition of insulin release by cyclooxygenase inhibitors was reported also by others. ${ }^{46}$ Scrutiny of our data reveals that FLR promoted insulin release when cyclooxygenase was inhibited profoundly and only in the presence of high concentrations of glucose, particularly when fetal calf serum had been added. Availability of glucose or serum are conditions leading to activation of phospholipase $A_{2}$ and ensuing increase in available arachidonate. Thus, with strong but not with mild inhibition of cyclooxygenase the circumstances may have been suitable for the shunting of arachidonate into the lipoxygenase pathways. We have shown that administered leukotrienes, which are products of 5 -lipoxygenase pathway, stimulate insulin release. ${ }^{49}$ Metz et $\mathrm{al}^{42}$ observed that 12-hydroperoxyeicosatetraenoic acid, a 12-lipoxygenase product, evoked insulin secretion. The inhibition of insulin release with NDGA that we documented in this study is consonant with our findings on arginine-induced and glucoseinduced insulin release from the perfused rat pancreas. ${ }^{48.50}$ Yamamoto et $\mathrm{al}^{5,6}$ and Metz et al ${ }^{42,51}$ made similar observations to support that lipoxygenase pathway products promote insulin secretion. If, in our experiments with $10 \mu \mathrm{mol} / \mathrm{L}$ FLR, these compounds and other yet-to-be-identified insulin secretagogues were produced in abundance, they could have been responsible for the enhancement of insulin release. This paradigm demands that the increases in insulin release that occur upon the inhibition of cyclooxygenase when there is abundant arachidonate be abolished by the inhibition of lipoxygenases. Our results with the administration of FLR and NDGA in combination demonstrate this predicted response. We have shown previously that $\mathrm{PGE}_{2}$ as well as other prostaglandins are secretagogues of insulin. ${ }^{16-18}$ The fact that the degree of inhibition of insulin release with FLR plus NDGA was greater than that with NDGA alone is an indication that the attenuating effect of decreased prostaglandin synthesis on insulin release was being masked by increased production of insulin secretagogues in the lipoxygenase pathways. Also, BPB inhibited insulin release at a magnitude greater than that induced by NDGA alone and similar to that induced by FLR plus NDGA. The inhibition of prostaglandin synthesis that we documented by the decreases in $\mathrm{PGE}_{2}$ levels, as well as the presumed inhibition of synthesis of lipoxygenase products must have contributed to BPB-induced attenuation of insulin release. A similar reasoning is applicable to the interpretation of the inhibitory effects of NDGA on insulin release. In the present set of experiments $\mathrm{PGE}_{2}$ levels decreased with NDGA, and the addition of FLR intensified the inhibition of insulin secretion that occurred with NDGA. Thus, if the inhibition of lipoxygenases is the primary mechanism by which insulin secretion was inhibited, the inhibition of cyclooxygenase appears to have assisted in this action. Nevertheless, in other experiments ${ }^{48}$ we documented the ability of NDGA to suppress insulin release in the absence of any decreases in prostaglandin biosynthesis, so that the ability of NDGA to inhibit insulin release by mechanisms other than the inhibition of cyclooxygenase cannot be disputed.

We and others have shown previously that a variety of prostaglandins, including $\mathrm{PGE}_{2}$, stimulate the secretion of glucagon. ${ }^{16-19,52}$ Furthermore, we and others have observed that cyclooxygenase inhibitors inhibit glucagon release..$^{19,22,48,53}$ The reason for failure of FLR to inhibit glucagon release in many of our present experiments, at a time it inhibited $\mathrm{PGE}_{2}$ release is not obvious. Analogous to the interpretation of the effects of FLR on insulin release, one may postulate that lipoxygenase pathway products also promote glucagon secretion, and increased production of arachidonate metabolites as a result of the putative substrate shunting could prevent the inhibition of glucagon secretion. This postulate in not tenable, because with NDGA glucagon secretion was increased, and because in another study we did not 
observe a clear stimulation of glucagon release by leukotrienes which are secretagogues of insulin. ${ }^{49}$ On the other hand, the products of a pathway of arachidonate metabolism other than lipoxygenase may have been involved: Falck et $\mathrm{al}^{54}$ reported recently that certain epoxyeicosatrienoic acids, which are products of the epoxygenase pathway of arachidonate metabolism, stimulate glucagon release. At the moment no information is available on the activity of this metabolic pathway in the pancreas or pancreatic islets, so that its involvement in the action of FLR we have observed in this study is highly speculative.

NDGA stimulated glucagon secretion and FLR abolished this effect. The information on the involvement of the lipoxygenase pathway products in the regulation of glucagon secretion is very limited and has originated exclusively from our laboratory. ${ }^{48,49}$ Based on other observations of the effects of NDGA and exogenous leukotrienes, we concluded that the lipoxygenase pathways play a minor or insignificant role in regulation of secretion of glucagon. Our earlier data do not support or disrepute an interpretation of NDGA effects in the present study that endogenous lipoxygenase products exert an inhibitory influence on glucagon secretion. The observed abolition of the effect of NDGA by FLR could be an independent action and hence cannot be used as evidence against the putative role of endogenous lipoxygenase products as inhibitors of glucagon secretion. The gaps in knowledge in this area are too large to reach definitive conclusions at this time.

We conclude that increased metabolism of arachidonic acid in pancreatic islets amplifies the secretion of insulin and glucagon. The lipoxygenase as well as the cyclooxygenasc pathways of arachidonatc metabolism participate in the amplification of insulin secretion. The observations made in this study are inconclusive with respect to the involvement of the two metabolic pathways in glucagon secretion; an inhibitory role for lipoxygenase pathway products is suggested.

\section{ACKNOWLEDGMENTS}

Flurbiprofen and the reagents for the $\mathrm{PGE}_{2}$ RIA were kindly donated by the Upjohn Company, Kalamazoo, MI. Dr Morgan was a research fellow sponsored by the Juvenile Diabetes Foundation International. This work was supported in part by USPHS grants AM 21192, AM 20752 and AM 07245 from the National Institute of Arthritis, Diabetes, Digestive and Kidney Diseases.

\section{REFERENCES}

1. Morgan RO, Pek SB: Endogenous lipoxygenase products may play a stimulatory role in glucose-induced insulin secretion from rat pancreatic islets. Program, Fifth International Conference on Prostaglandins, Florence, May 19-21, 1982, p 114.

2. Clements RS Jr, Rhoten WB: Phosphoinositide metabolism and insulin secretion from isolated rat pancreatic islets. $J$ Clin Invest 57:684-691, 1976

3. Kelly KL, Laychock SG: Prostaglandin synthesis and metabolism in isolated pancreatic islets of the rat. Prostaglandins 21:759769,1981

4. Laychock SG: Phospholipase $A_{2}$ activity in pancreatic islets is calcium-dependent and stimulated by glucose. Cell Calcium 3:4354,1982

5. Yamamoto $S$, Nakadate $T$, Nakaki $T$, et al: Prevention of glucose-induced insulin secretion by lipoxygenase inhibitor. Eur $\mathrm{J}$ Pharmacol 78:225-227, 1982

6. Yamamoto S, Nakadate T, Nakaki T, et al: Tumor promoter 12-tetradecanoylphorbol-13-acetate-induced insulin secretion: Inhibition by phospholipase $\mathrm{A}_{2^{-}}$and lipoxygenase-inhibitors. Biochem Biophys Res Commun 105:759-765, 1982

7. Weber PC, Scherer B, Larsson C: Increase of free arachidonic acid by furosemide in man as the causc of prostaglandin and renin release. Eur J Pharmacol 41:329-332, 1977

8. Ahnfelt-Ronne I: In vitro stimulation of prostaglandin synthesis by methyl xanthines. Prostaglandins 16:540-547, 1978

9. Levine, L, Pong S-S, Hong SL, Tam S: Deacylation of phospholipids: Prerequisite for prostaglandin synthesis by transformed fibroblasts, in Karasch N, Fried J (eds): Biochemical Aspects of Prostaglandins and Thromboxanes. New York, Academic Press, 1977, pp 15-38

10. Landgraf $R$, Landgraf-Leurs MMC: The prostaglandin system and insulin release. Studies with the isolated perfused rat pancreas. Prostaglandins 17:599-613, 1979
11. Turtle JR, Littleton GK, Kipnis DM: Stimulation of insulin secretion by theophylline. Nature 213:727-728, 1967

12. Morgan RO, Pek SB: Glucose evokes dose-related increases in prostaglandin and insulin secretion from incubated rat islets. Diabetes 31 (Suppl 2):25A, 1982

13. Blackwell GJ, Carnuccion R, DiRosa M, et al: A polypeptide causing the anti-phospholipase effect of glucocorticoids. Nature 287:147-149, 1980

14. Katsumata M, Gupta C, Baker MK, et al: Diphenylhydantoin: An alternative ligand of a glucocorticoid receptor affecting prostaglandin generation in $\mathbf{A} / \mathbf{J}$ mice. Science 218:1313-1315, 1982

15. Johnson DG, Fujimoto WY, Williams RH: Enhanced release of insulin by prostaglandins in isolated pancreatic islets. Diabetes 22:658-663, 1973

16. Pek S, Tai T-Y, Elster A, Fajans SS: Stimulation by prostaglandin E-2 of glucagon and insulin release from isolated rat pancreas. Prostaglandins 10:493-502, 1975

17. Pek S, Tai T-Y, Elster A: Stimulatory effects of prostaglandins $\mathrm{E}-1, \mathrm{E}-2$ and $\mathrm{F}-2$-alpha on glucagon and insulin release in vitro. Diabetes 27:801-809, 1978

18. Pek S, Lands WEM, Akpan J, et al: Effects of prostaglandins $\mathrm{H}_{2}, \mathrm{D}_{2}, \mathrm{I}_{2}$ and thromboxane on in vitro secretion of glucagon and insulin. Adv Prostaglandin Thromboxane Res 8:1295-1298, 1980

19. Giugliano D, Torella R, D'Onofrio F: Prostaglandins and the alpha cell. Prostaglandins Med 6:283-297, 1981

20. Schusdziarra V, Rouiller D, Harris V, et al: Effect of prostaglandin $E_{2}$ upon release of pancreatic somatostatin-like immunoreactivity. Life Sci 28:2099-2102, 1981

21. Nishi $S$, Seino $Y$, Seino $S$, et al: Prostaglandin $E_{1}:$ Stimulation of somatostatin and insulin responses to glucose from the isolated perfused rat pancreas. Prostaglandins Leukotrienes Med $8: 593-597,1982$ 
22. Spangler RS, Pek SB: Effects of cyclooxygenase inhibition on prostaglandin production and insulin and glucagon secretion by isolated rat islets. Adv Prostaglandin Thromboxane Leukotriene Res 12:291-298. 1983

23. Broadie TA, Bybee D, Fletcher JR, et al: Indomethacininduced augmentation of insulin release. J Surg Res 30:275-280, 1981

24. Metz SA, Robertson RP, Fujimoto WY: Inhibition of prostaglandin $E$ synthesis augments glucose-induced insulin secretion in cultured pancreas. Diabetes 30:551-557, 1981

25. Burr IM, Sharp R: Effects of prostaglandin $E_{1}$, and epinephrine on the dynamics of insulin release in vitro. Endocrinology 94:835-839, 1974

26. Roberston RP: Prostaglandins, glucose homeostasis, and diabetes mellitus. Med Clin North Am 65:759-771, 1981

27. Bryant RW, Bailey JM: Isolation of glucose-sensitive lipoxygenase products from arachidonic acid. Adv Prostaglandin Thromboxane Res 6:95-99, 1980

28. Levasseur S, Sun FF, Friedman Y, et al: Arachidonate metabolism in the mouse thyroid. Implication of the lipoxygenase pathway in thyrotropin secretion. Prostaglandins 22:663-673, 1981

29. Lacy PE, Kostianovsky M: Method for the isolation of intact islets of I angerbans from the rat pancreas. Diabetes 16:35-39, 1967

30. Vargaftig BB, Fouque $F$, Chignard $M$ : Interference of bromophenacyl bromide with platelet phospholipase $A_{2}$ activity induced by thrombin and by the ionophore A23187. Thromb Res 17:91-102, 1980

31. Rome LH, Lands WEM: Structural requirements for timedependent inhibition of prostaglandin biosynthesis by anti-inflammatory drugs. Proc Nat Acad Sci USA 72:4863-4865, 1975

32. Brogden RN, Heel RC, Speight TM, et al: Flurbiprofen: A review of its pharmacological properties and therapeutic use in rheumatic diseases. Drugs 18:417-438, 1979

33. Hamberg $M$ : On the formation of thromboxane $B_{2}$ and 12L-hydroxy-5, 8, 10, 14-eicosatetraenoic acid (12ho-20:4) in tissues from the guinea pig. Biochim Biophys Acta 431:651-654, 1976

34. Hammerstrom S, Falardeau P: Resolution of prostaglandin endoperoxide synthase and thromboxane synthase of human platelets. Proc Nat Acad Sci USA 74:3691-3695, 1977

35. Parker $\mathrm{CW}$, Stenson WF, Huber MG, et al: Formation of thromboxane $\mathbf{B}_{2}$ and hydroxy-arachidonic acids in purified human lymphocytes in the presence and absence of PHA. J Immunol 122:1572-1577, 1979

36. Morris HR, Piper PJ, Taylor GW, et al: The role of arachidonate lipoxygenase in the relcase of SRS-A from guinea-pig chopped lung. Prostaglandins 19:371-383, 1980

37. Pek S: Glucagon and insulin, in Rothfeld B (ed): Nuclear Medicine: Endocrinology. Philadelphia, Lippincott, 1978, pp 122140

38. Fitzpatrick FA, Bundy GL: Hapten mimic elicits antibodies recognizing prostaglandin $E_{2}$. Proc Natl Acad Sci USA 75:26892693,1978

39. Montgomery DC: Design and Analysis of Experiments. Wiley and Sons, New York, 1976

40. Lee W: Experimental Design and Analysis. Freeman and Co. San Francisco, 1975

41. Metz S, Robertson RP, Fujimoto W: Inhibition of PGE synthesis augments glucose-induced insulin secretion in cultured pancreas. Diabetes 30:551-557, 1981

42. Metz S, VanRollins M, Strife R, et al: Lipoxygenase pathway in islet endocrine cells. Oxidative metabolism of arachidonic acid promotes insulin release. J Clin Invest 71:1191-1205, 1983

43. Phair RD, Pek SB, Lands WEM: Arachidonic acid-induced release of insulin and glucagon: Role of endogenous prostaglandins in pancreatic hormone secretion. Diabet Metab (in press)

44. Feuerstein N, Bash JA, Woody JN, et al: Leukotriene C stimulates prostaglandin release from rat peritoneal macrophages. Biochem Biophys Res Commun 100:1085-1090, 1981

45. Engineer DM, Niederhauser U, Piper PJ, et al: Release of mediators of anaphylaxis: Inhibition of prostaglandin synthesis and the modification of release of slow-reacting substances of anaphylaxis and histamine. Br J Pharmacol 62:61-66, 1978

46. Robertson RP: Hypothesis: PGE, carbohydrate homeostasis, and insulin secretion: A suggested resolution of the controversy. Diabetes 32:231-235, 1983

47. MacAdams MR, Pek SB, Lands WEM: The effect of flurbiprofen, a potent inhibitor of prostaglandin synthesis, on insulin and glucagon release from isolated rat pancreas. Endocrinology 114:1365-1370, 1984

48. Walsh MF, Pek SB: Possible role of endogenous arachidonic acid metabolites in stimulated release of insulin and glucagon from the isolated perfused rat pancreas. Diabetes (in press)

49. Pek SB, Walsh MF: Leukotrienes stimulate insulin release from the rat pancreas. Proc Natl Acad Sci USA 81:2199-2202. 1984

50. Walsh MF, Pek SB: Effects of lipoxygenase and cyclooxygenase inhibitors on glucose-stimulated insulin secretion from the isolated perfused rat pancreas. Life Sci 34:1699-1706, 1984

51. Metz SA, Fujimoto WY, Robertson RP: A role for the lipoxygenase pathway of arachidonic acid metabolism in glucoseand glucagon-induced insulin secretion. Life Sci 32:903-910, 1983

52. Sacca L, Perez G: Influence of prostaglandins on plasma glucagon levels in the rat. Metabolism 25:127-130, 1976

53. Luyckx AS, Lefebvre PJ: Possible role of endogenous prostaglandins in glucagon secretion by isolated guinea-pig islets. Diabetologia 15:411-416, 1978

54. Falck JR, Manna S, Moltz J, et al: Epoxyeicosatrienoic acids stimulate glucagon and insulin release from isolated rat pancreatic islets. Biochem Biophys Res Commun 114:743--749, 1983 